\title{
Ultrafine-Grained Ti-13Nb-13Zr Alloy Produced by Severe Plastic Deformation
}

\author{
Diego Alfonso Godoy Pérez *, Alberto Moreira Jorge Junior ${ }^{a}$, Claudio Shyinti Kiminami \\ Claudemiro Bolfarini ${ }^{a}$, Walter Jose Botta ${ }^{a}$
}

\author{
${ }^{a}$ Departamento de Engenharia de Materiais - DEMa, Universidade Federal de São Carlos - UFSCar, \\ São Carlos, SP, Brazil
}

Received: January 15, 2017; Revised: August 24, 2017; Accepted: August 31, 2017

\begin{abstract}
Biomedical devices currently in use (prostheses, implants) have satisfactory performance in many cases. However, sometimes the body reacts to the device insertion and may lead to its rapid replacement. Some of these disadvantages can be solved by the use of titanium and its alloys, due to their excellent combination of corrosion resistance, wear resistance and biocompatibility compared to other competing biomaterials. This paper presents the possibility of obtaining near beta titanium alloy with ultrafine grains produced by severe plastic deformation. For this, the Ti-13Nb-13Zr alloy was processed by high-pressure torsion processing method. Samples were processed with different loads and number of turns. After characterization, it was observed that after applying three turns, a load of $1 \mathrm{GPa}$ produces more Ti-beta phase than a load of $6 \mathrm{GPa}$. However, as expected, the larger the load, the higher the refinement.
\end{abstract}

Keywords: Severe plastic deformation, Ultrafine grained, Ti-13Nb-13Zr.

\section{Introduction}

For several decades, metallic biomaterials have been used extensively for surgical implants due to their good formability, high strength, and resistance to fracture ${ }^{1}$. In addition to the mechanical stability under physiological stresses and strains, implant materials should be able to perform with an appropriate host response in a specific situation ${ }^{2}$. The key for understanding biocompatibility is the determination of which (and why) chemical, biochemical, physiological, physical or other mechanisms become operative under highly specific conditions associated with contact between biomaterials and the tissues of the body, and what are the consequences of these interactions ${ }^{3}$.

The use of Titanium and its alloys as biomaterial is increasing because of its low modulus of elasticity (twice as low as Co-Cr alloys or stainless steels), which results in less stress shielding and bone resorption associated with implants $^{2}$. Commercially pure titanium (CPTi) and many of the $\alpha+\beta$ - type Ti-based alloys, including the most commercially available Ti-6Al-4V alloy, were designed for structural use in the aerospace industry ${ }^{4}$. Later they were used in biomedical applications. The toxicity of the vanadium, a strong stabilizer of the $\beta$ phase, has been demonstrated. Thus, $V$ has been replaced by other $\beta$-stabilizing elements, such as $\mathrm{Fe}$ or $\mathrm{Nb}^{5-7}$. The $\beta$-rich Ti-13Nb-13Zr alloy is an alternative with great possibilities for biomedical applications due to its mechanical resistance and low modulus of elasticity, besides having highly biocompatible alloying elements such as niobium $(\mathrm{Nb})$ and zirconium $(\mathrm{Zr})^{8}$.

Nanostructured materials have potential application in the biomedical area since they seem to present a better cellular response, making these materials an important focus for the application as biomaterials. The most promising approach for producing nanostructured materials is to refine coarse-grained metal through severe plastic deformation (SPD). Processes of SPD may be defined as metal forming processes in which an ultra-large plastic strain is introduced into a bulk metal in order to create ultra-fine grained metals ${ }^{9-11}$. The most developed SPD techniques are equal channel angular pressing (ECAP) and high-pressure torsion (HPT) $)^{12}$. During HPT processing, a disk-shaped sample is positioned between two anvils that apply a compression pressure of several gigapascals at room temperature, simultaneously to a torsional deformation which is imposed through rotation of the lower support ${ }^{13}$.

The present study intended to analyze the microstructure and microhardness of the Ti-13Nb-13Zr alloy that underwent severe plastic deformation through the HPT technique. Samples were structurally characterized by X-ray diffraction (XRD) and microstructurally by scanning (SEM) and transmission (TEM) electron microscopy. Mechanical properties were evaluated through hardness tests, whose results were discussed as a function of the microstructural evolution. 


\section{Experimental}

\subsection{Methods}

The material used in this study was the biomedical $\beta$-rich Ti-13Nb-13Zr alloy (ERCATA GmbH, Development Co., Ltd., Germany). The chemical analysis of the alloy is shown in Table 1.

The alloy was heat-treated at $750^{\circ} \mathrm{C}$ for 1 hour followed by furnace cooling, producing an initial coarse-grained microstructure with an $(\alpha+\beta)$ structure (see Figure 1).

The HPT process was performed on polished disks with a diameter of $7.0 \mathrm{~mm}$ and a thickness of about $0.65 \mathrm{~mm}$. The processing was performed at room temperature. Disks were processed under pressures of 1.0, 4.5 and 6.0 GPa. Three turns were applied using a rotation speed of $3 \mathrm{rpm}$.

Scanning electron microscopy (SEM) using a Phillips XL 30 FEG and an FEI Inspect S50 model and optical microscopy (OM) using a ZEISS Imager A1.m were used to investigate the microstructure.

Conventional transmission microscopy and Orientationphase mapping were accomplished by transmission electron microscopy (TEM) using an FEI TECNAI G2 operated at 200 $\mathrm{KV}$. This facility is equipped with an orientation and phase mapping precession unit NanoMEGAS (model ASTAR) and with a Digistar P1000 unit. The recently developed technique based on transmission electron microscopy, called ASTAR, makes use of electron-beam (in precession mode or not) together with spot diffraction pattern recognition, offering the opportunity to perform Automated Crystal Orientation Mapping (ACOM) in micro- or nanoprobe mode. ACOM-TEM opens the opportunity of acquiring reliable orientation/phase maps with a spatial resolution that can go down to the nm range. In short, the ACOM-TEM consists in scanning the electron beam (in precession or not) in the nanoprobe mode on a specimen area, thus collecting, by a CCD cam, thousands of electron diffraction spot patterns to be subsequently indexed automatically through a template matching. In fact, and very important, ACOM-TEM closes the gap between EBSD in SEM and bright field (BF)/dark field (DF) in TEM by providing full orientation maps with nanometer resolution and even materials severely plastic deformed (SPD), e.g., by ECAP or HPT, can be reliably analyzed. When SPD is performed, problems can arise when observations by EBSD are carried out, because of the Kikuchi lines, used by any EBSD system or in the TEM, are very sensitive to the crystal orientation, and they rapidly disappear if the diffracting volume suffers distortions induced by high dislocation densities ${ }^{14}$.

Samples for OM and SEM were ground in a multistep process using $\mathrm{SiC}$ abrasive paper (320,400, 600, 800, 1200 and 2000 grit). After grinding, the Keller's reagent was used to etch the samples $(1.5 \mathrm{ml}$ hydrochloric acid, $1 \mathrm{ml}$ hydrofluoric acid, $2.5 \mathrm{ml}$ nitric acid and $95 \mathrm{ml}$ distilled water).

TEM samples were thinned down to $10 \mu \mathrm{m}$ by a Gatan Dimple Grinder (model 656) using diamond polishing paste and alumina suspension. The final stage of sample preparation was ion milling using a Gatan Precision Ion Polishing System (model 691) under conditions in which damage is avoided in the structure during thinning $(2.5 \mathrm{keV}$ at the initial stage of polishing and $1.6 \mathrm{keV}$ at the final stage).

Phase identification was conducted by X-ray diffraction using a Rigaku ME210GF2 apparatus with $\mathrm{Cu} \mathrm{K} \alpha$ radiation and scanning speed of $2 \% \mathrm{~min}$ from $30^{\circ}$ to $90^{\circ}$.

Vickers microhardness ( $\mathrm{mHV}$ ) was performed using the Stiefelmayer microdurometer by applying a load of $300 \mathrm{~g}$ during $15 \mathrm{~s}$. Microhardness mapping was performed along the radius from the center to edge at different radial directions.

Table 1. The chemical analysis (in wt $\%$ ) of the fabricated alloy.

\begin{tabular}{cccccccccc}
\hline & $\mathrm{O}$ & $\mathrm{N}$ & $\mathrm{C}$ & $\mathrm{Fe}$ & $\mathrm{Zr}$ & $\mathrm{Nb}$ & & & \\
$\mathrm{Wt} \%$ & 0.004 & 0.007 & 0.016 & 0.004 & 13.7 & 13.6 & Balance & \\
\hline
\end{tabular}
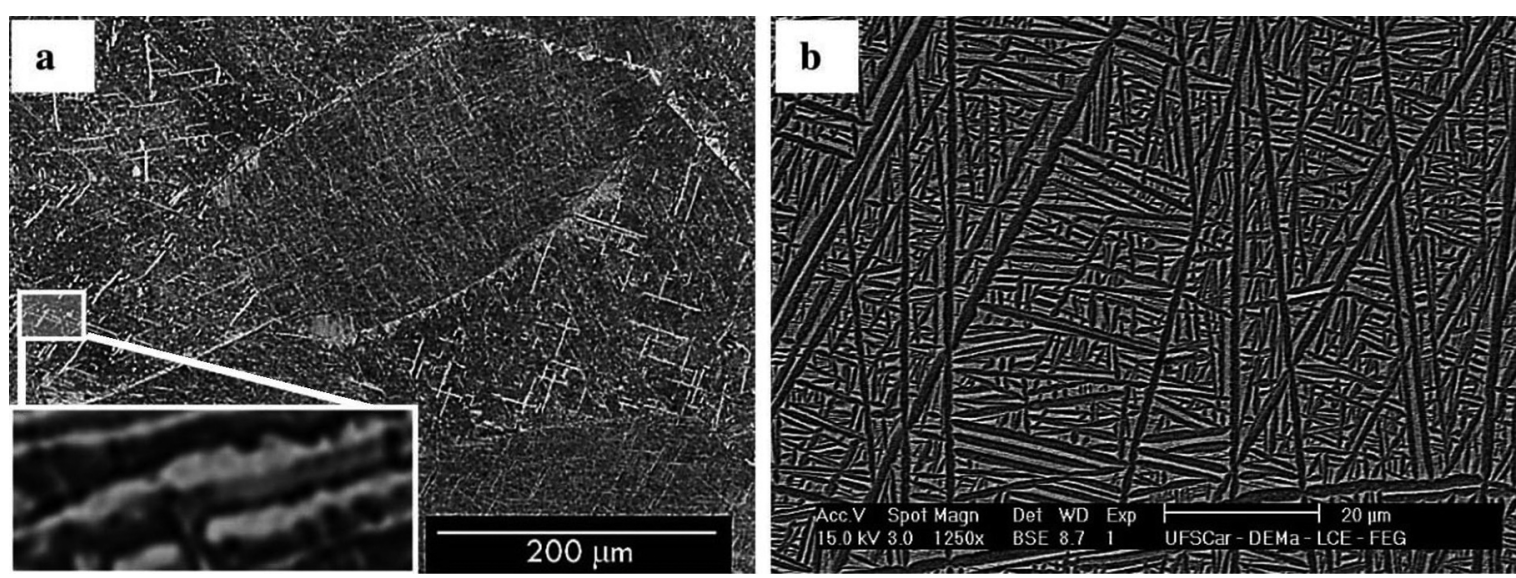

Figure 1. Micrographs showing the microstructure of $\mathrm{Ti}-13 \mathrm{Nb}-13 \mathrm{Zr}$ alloy in the initial state: a) OM, where the white needle-like microstructure is the $\alpha$-phase embedded in the dark grains of $\beta$-phase. b) SEM. 


\section{Results and Discussion}

\subsection{Microstructural observations}

OM and SEM micrographs are presented in Figure 2 for samples processed in three different pressures after three turns. Figures $2 \mathrm{a}$ and $2 \mathrm{~d}(1 \mathrm{GPa})$ show a microstructure consisted by the needle-like $\alpha$ embedded in $\beta$ grains. Increasing the pressure to $4.5 \mathrm{GPa}$ during processing through HPT the $\alpha$-laths bend due to the high strain (Figures $2 b$ and $2 \mathrm{e}$ ). After applying $6 \mathrm{GPa}$, the microstructure shows mostly globular $\alpha$ phase (Figures $2 \mathrm{c}$ and $2 \mathrm{f})^{15}$.

Figures $3 \mathrm{a}(1 \mathrm{GPa}), 3 \mathrm{~d}(4.5 \mathrm{GPa})$ and $3 \mathrm{~g}(6 \mathrm{GPa})$ show bright field TEM images taken at the longitudinal section of the processed Ti-13Nb-13Zr alloy. In these images, it is possible to observe a clear evidence for a multimodal distribution of grains. Measurements gave average grain/subgrain sizes of $\sim 500 \mathrm{~nm}, \sim 200 \mathrm{~nm}$, and $\sim 20 \mathrm{~nm}$, respectively for $1 \mathrm{GPa}$, $4.5 \mathrm{GPa}$, and $6 \mathrm{GPa}$. In addition, Figure 3 shows evidence that there are still large numbers of dislocations within the grains, meaning that samples are not totally recrystallized.

Orientation mappings were performed using TEM in the same regions of the alloy as shown in Figures 3a, $3 \mathrm{~d}$ and $3 \mathrm{~g}$ and the mappings are shown in Figures $3 \mathrm{~b}$, $3 \mathrm{e}$ and $3 \mathrm{~h}$, respectively for $1 \mathrm{GPa}, 4.5 \mathrm{GPa}$ and $6 \mathrm{GPa}$. These mappings are similar to the ones obtained by using electron backscatter diffraction (EBSD) in scanning electron microscopy (SEM) with the exception of that they have a higher resolution so that they can be used with nanometric sizes, providing the capability for performing the analysis in heavily deformed samples, a big issue for $\mathrm{EBSD}^{14}$, as after processing by HPT.

Aiming a comparison, Figures $3 \mathrm{~b}, 3 \mathrm{e}$, and $3 \mathrm{~h}$ are presenting equivalent bright field images obtained by regular TEM for the longitudinal section of the Ti-13Nb-13Zr alloy. These images show an inhomogeneous distribution of grains/subgrains. It is worth noting that, albeit these images have been taken in the same regions as in Figures $3 \mathrm{a}, 3 \mathrm{~d}$, and $3 \mathrm{~g}$, the sets of images are not identical because of Figures $3 \mathrm{~b}, 3 \mathrm{e}$, and $3 \mathrm{~h}$ were taken already with orientation information and promptly differentiate between boundaries and sub-boundaries. Misorientation angles of boundaries were indexed, and Figures $3 \mathrm{~b}, 3 \mathrm{e}$, and $3 \mathrm{~h}$ show high-angle boundaries (blue) with misorientation angles equal to or greater than $15^{\circ}$ and low-angle grain boundaries (red) having misorientation angles less than $15^{\circ}$. High-angle boundaries are related to the presence of new grains and low-angle boundaries to sub-grains.

Table 2 summarizes all the features observed in the OIM and phase analyses, where, after indexing the colors of boundaries, one can see that the high-loaded samples contain $\sim 76.8 \%$ of high-angle boundaries on average, and sample processed at $1 \mathrm{GPa}$ reached the maximum amount $(84.6 \%)$ or, in other words, it reached a more recrystallized stated than the samples processed using higher loads. This analysis, in fact, confirms the observations from Figures $3 \mathrm{a}$, $3 \mathrm{~d}$, and $3 \mathrm{~g}$ concerning the amount of deformation still present in the samples. In fact, recent studies regarding ultrafine
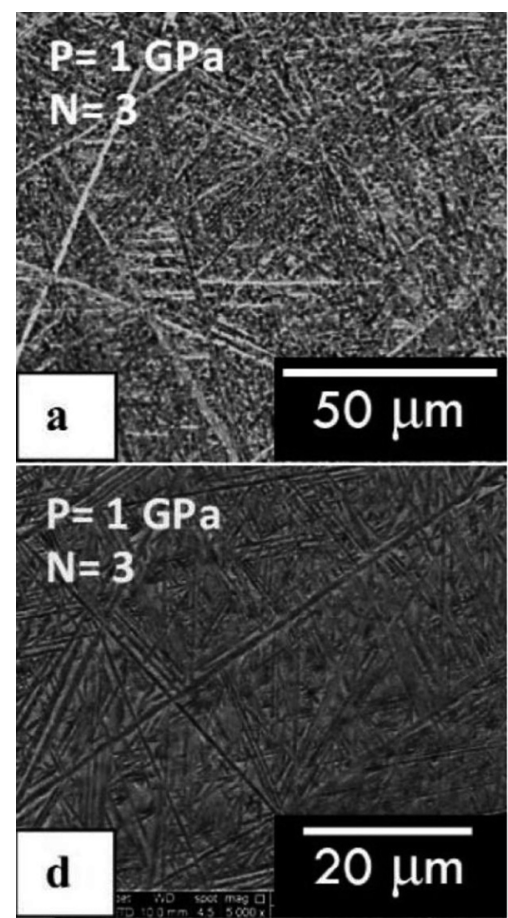
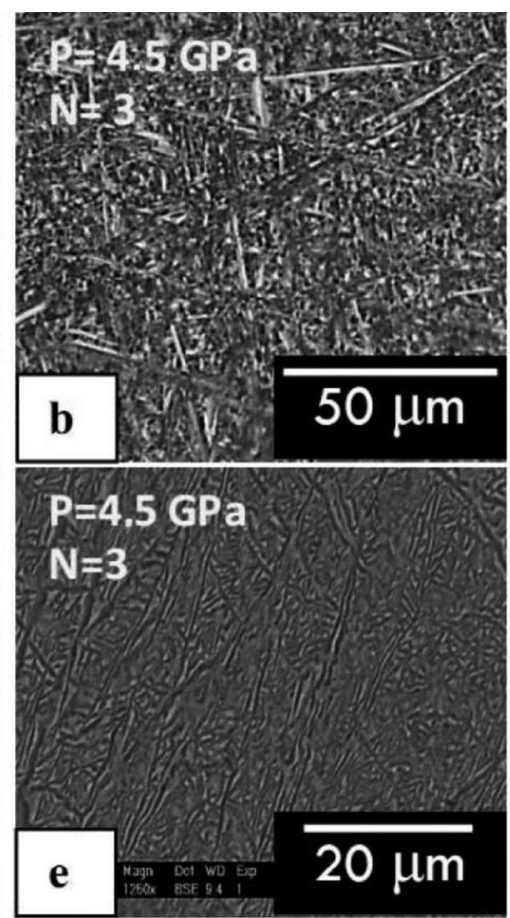
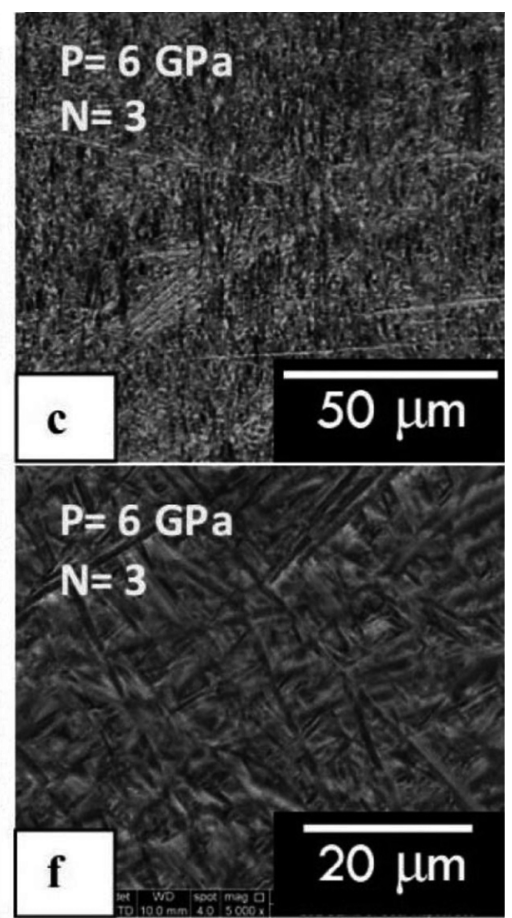

Figure 2. OM (a, b, c) and SEM (d, e, f) micrographs showing microstructures of the severely plastically deformed Ti-13Nb-13Zr alloy. The conditions are specified in the figures, where $\mathrm{N}$ means the number of turns. 


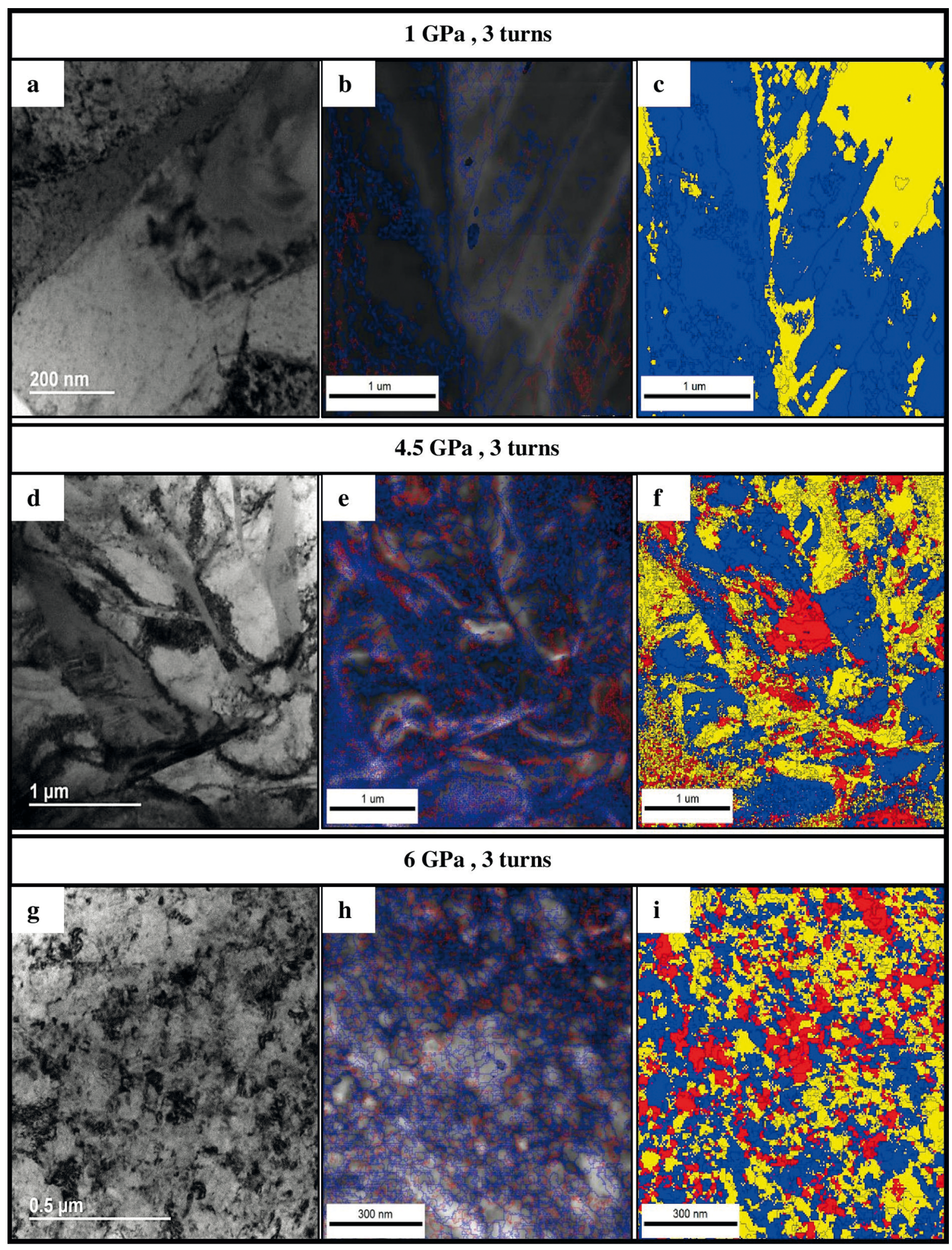

Figure 3. TEM examination after HPT processing; (a), (d) and (g) Virtual bright field; (b), (e) and (h) The grain boundary distribution maps; (c), (f) and (i) Phase map.

grained materials (UFG) explain that Non-equilibrium grain boundaries exist in UFG materials, and these specific grain boundaries possess an increased free energy density, increased width, high density of dislocations (full or partial) associated with the near-boundary region and correspondingly large residual microstrain ${ }^{16}$. 
Table 2. Different types of grain boundaries after HPT processing.

\begin{tabular}{|c|c|c|c|c|c|c|}
\hline \multirow{4}{*}{$\begin{array}{c}\text { Type of } \\
\text { boundaries }\end{array}$} & \multicolumn{6}{|c|}{ Pressure } \\
\hline & \multicolumn{2}{|c|}{$1 \mathrm{GPa}$} & \multicolumn{2}{|c|}{$4.5 \mathrm{GPa}$} & \multicolumn{2}{|c|}{$6 \mathrm{GPa}$} \\
\hline & \multicolumn{2}{|c|}{3 turns } & \multicolumn{2}{|c|}{3 turns } & \multicolumn{2}{|c|}{3 turns } \\
\hline & Fraction & Number & Fraction & Number & Fraction & Number \\
\hline $\begin{array}{c}\text { Low-angle } \\
\left(\text { from } 2^{\circ} \text { to } 15^{\circ} \text { ) }\right.\end{array}$ & $15.40 \%$ & 2839 & $22.70 \%$ & 23149 & $23.70 \%$ & 31913 \\
\hline $\begin{array}{c}\text { High-angle } \\
\text { (from } 15^{\circ} \text { to } 180^{\circ} \text { ) }\end{array}$ & $84.60 \%$ & 15606 & $77.30 \%$ & 78942 & $76.30 \%$ & 102480 \\
\hline $\begin{array}{c}\text { Twins } \\
(\Sigma 7 \mathrm{a}, \Sigma 7 \mathrm{~b} . \Sigma 13 \mathrm{a} . \\
\Sigma 13 \mathrm{~b}, \Sigma 19 \mathrm{a}, \Sigma 19 \mathrm{~b})\end{array}$ & $7.53 \%$ & 586 & $7.70 \%$ & 490 & $5.20 \%$ & 530 \\
\hline
\end{tabular}

Distributions of grain size are presented in Figure 4 for the processed samples in the longitudinal section. The distributions confirm the observation from Bright Field TEM images regarding multimodality of grain sizes, which is expected in the initial stages ( 3 turns) of the HPT processing. The measured average grain sizes were $\sim 497 \mathrm{~nm}, 126.3 \mathrm{~nm}$, and $15.25 \mathrm{~nm}$, respectively for $1 \mathrm{GPa}, 4.5 \mathrm{GPa}$, and $6 \mathrm{GPa}$. These values are similar to the ones obtained from analysis of the BF-TEM images in Figures 3a, 3d, and $3 \mathrm{~g}$.

Mappings of phases are presented in Figures 3c, 3f, and $3 \mathrm{i}$, respectively for $1 \mathrm{GPa}, 4.5 \mathrm{GPa}$ and $6 \mathrm{GPa}$. Table 3 summarizes phases present in each condition as well as their fractions. Figure 3(c) shows the presence of only $\alpha$ phase (yellow color) and $\beta$ phase (blue color), the proportions of these phases are: $24.7 \%$ for $\alpha$ phase and $75.3 \%$ for $\beta$ phase. When increasing the pressure, there are changes in both the kind and distribution of phases. When the load is increased to $4.5 \mathrm{GPa}$ (Figure $3 \mathrm{f}$ ) there is an increase of $\alpha$ phase (yellow color) from $24.7 \%(1 \mathrm{GPa})$ to $40,5 \%(4.5 \mathrm{GPa}), \beta$ phase (blue color) has a decrease from $75.3 \%$ to $42.1 \%$ and the $\omega$ phase (red color) starts to appear with a fraction of $17.4 \%$. With the highest pressure of $6 \mathrm{GPa}$ (Figure 3f), the phases are better distributed along the sample volume, and there is a slightly decrease of the $\alpha$ phase (yellow color) from $40.5 \%$ $(4.5 \mathrm{GPa})$ to $36.5 \%(6 \mathrm{GPa}), \beta$ phase is kept at a stable value (blue color), and the $\omega$ phase (red color) is increased from $17.4 \%$ to $21.1 \%$. This formation is consistent with previous studies reporting on the transformation from $\alpha$ phase to $\omega$ phase at pressures changing from 2.9 to $11 \mathrm{GPa}^{17}$. In fact, the presence of $\omega$ phase can be explained in two ways, firstly it is a high-pressure phase, and secondly, it is an intermediate phase regarding the transformation sequence of $\alpha$ into $\beta$ or $\beta$ into $\alpha$.

\subsection{Microhardness measurements}

Microhardness in Ti-13Nb-13Zr alloy as a function of the distance from the center of the disk-shaped samples after of 3 turns for different pressures are plotted in Figures 5a, $5 \mathrm{~b}, 5 \mathrm{c}$, and $5 \mathrm{~d}$, respectively for the initial condition, $1 \mathrm{GPa}$, $4.5 \mathrm{GPa}$, and $6 \mathrm{GPa}$. As one can observe, the microhardness increases with the increase of the pressure, which is related to the decreasing grain size. As it can be seen in Figure $5 \mathrm{~d}$, the microhardness value of Ti-13Nb-13Zr increases significantly for the pressure of $6 \mathrm{GPa}$ (from $223 \mathrm{HV}$ at the initial state to $412 \mathrm{HV}$ ). This analysis is in accordance with the study of Wang and Langdon ${ }^{18}$. Microhardness measurements have confirmed that the hardness increases with the distance from the center of the disc to the edge because, as the processing is torsional, the deformation decreases from the edge to the center, thus leading to smaller grains in the edge than in the center.

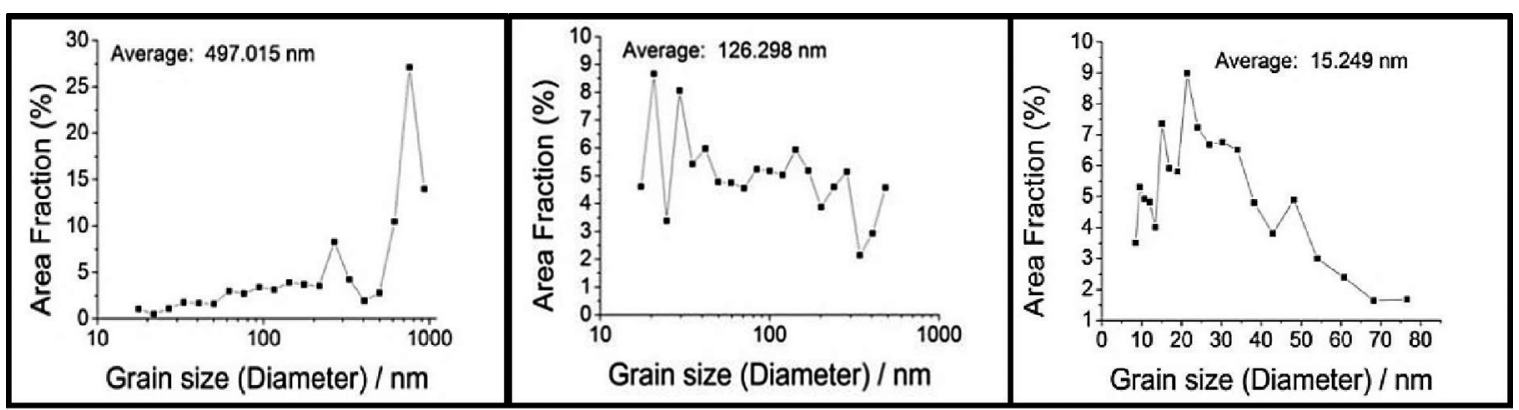

a) 1 GPa, 3 turns

b)

4.5 GPa, 3 turns

c)

6 GPa, 3 turns

Figure 4. (a), (b) and (c) Grain size distribution. 
Table 3. Phase distribution in samples deformed by HPT.

\begin{tabular}{lcccccccccc}
\hline \multirow{2}{*}{ Phase distribution } & \multicolumn{3}{c}{$1 \mathrm{GPa}, 3$ turns } & \multicolumn{3}{c}{$4.5 \mathrm{GPa}, 3$ turns } & \multicolumn{3}{c}{$6 \mathrm{GPa}, 3$ turns } \\
& $\alpha$ phase & $\beta$ phase & $\omega$ phase & $\alpha$ phase & $\beta$ phase & $\omega$ phase & $\alpha$ phase & $\beta$ phase & $\omega$ phase \\
\hline Fraction of phases (\%) & 24.7 & 75.3 & 0 & 40.5 & 42.1 & 17.4 & 36.5 & 42.4 & 21.1 \\
\hline
\end{tabular}
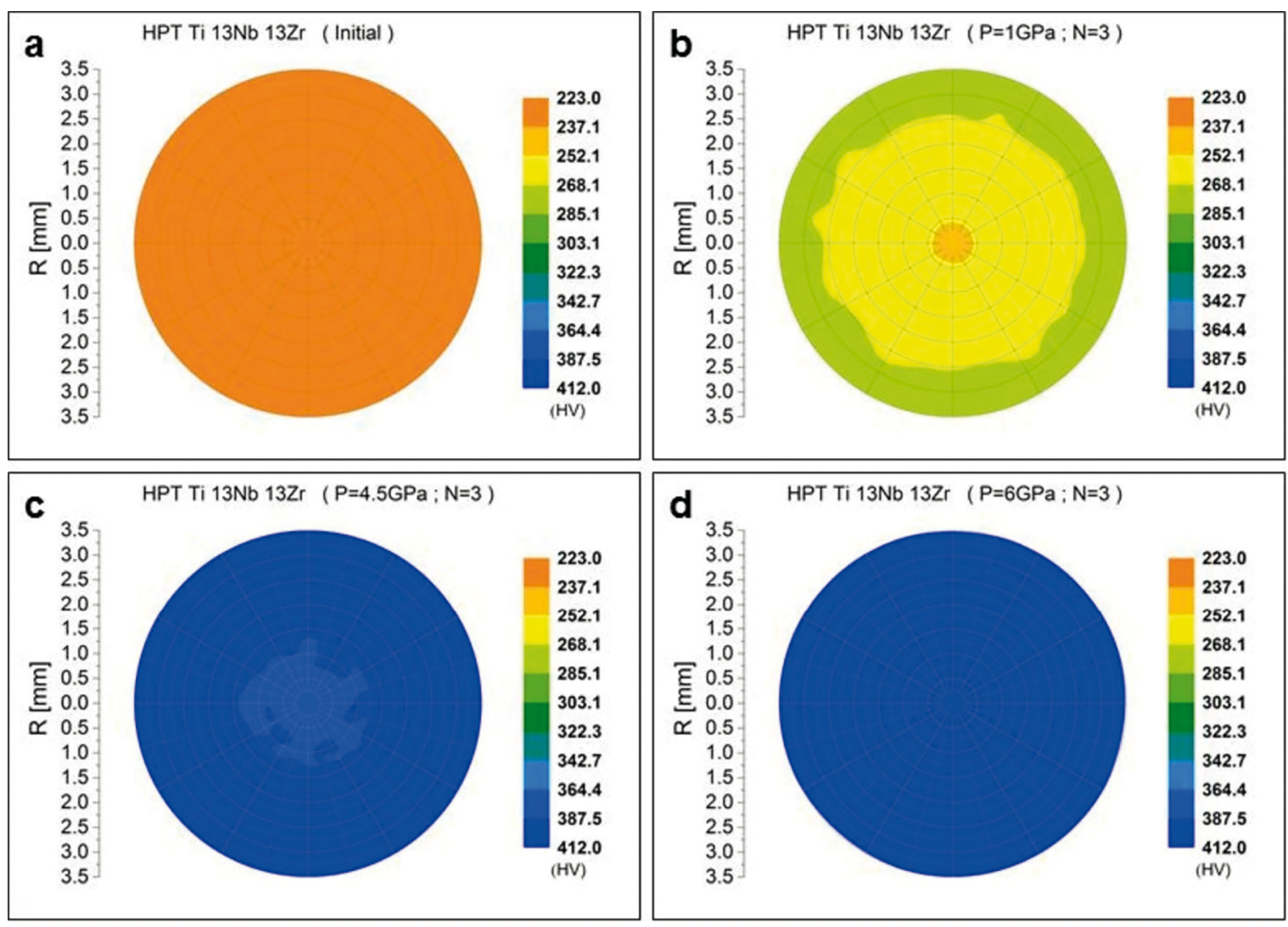

Figure 5. (a), (b), (c) and (d) Vickers microhardness of the Ti-13Nb-13Zr alloy as a function of the radial distance R.

\subsection{Characterization by $X$-ray diffraction}

$\mathrm{X}$-ray diffraction profiles were recorded for the starting material as well as for the HPT-processed samples using $\mathrm{Cu}-\mathrm{K} \alpha$ radiation. The constituent phases were identified from XRD patterns, as shown in Figure 6. The XRD profiles revealed Bragg-peaks corresponding to only $\alpha$ and $\beta$ phases in the initial condition and for the pressure of $1 \mathrm{GPa}$. The peak for $\omega$ phase appears for pressures of $4.5 \mathrm{GPa}$ and $6 \mathrm{GPa}$, confirming the above observations using OIM information and, as also commented, the already observed same behavior in the literature ${ }^{17}$.

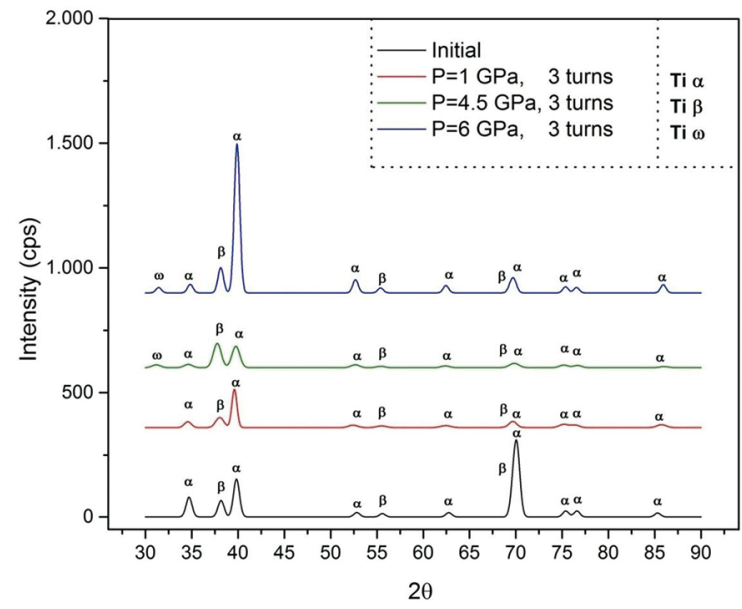

Figure 6. XRD patterns corresponding to samples processed by HPT. 


\section{Conclusions}

The following conclusions can be drawn from the present study:

- $\quad$ Ti-13Nb-13Zr alloy subjected to the HPT process resulted in considerable grain refinement, where the grains are smaller than 1 micron which places this material in the ultrafine grain category;

- There is a considerable increase in hardness, due to the great grain refinement and the partial transformation of the alpha phase to the omega phase;

- The alpha phase transformation to the omega phase is increased for pressures of $4.5 \mathrm{GPa}$ and $6 \mathrm{GPa}$ in the HPT process.

\section{References}

1. Mishnaevsky L Jr, Levashov E, Valiev RZ, Segurado J, Sabirov I, Enikeev N, et al. Nanostructured titanium-based materials for medical implants: Modeling and development. Materials Science and Engineering: R: Reports. 2014;81:1-19.

2. Sabirov I, Enikeev NA, Murashkin MY, Valiev RZ. Bulk Nanostructured Materials with Multifunctional Properties. New York: Springer; 2015.

3. Williams DF. On the mechanisms of biocompatibility. Biomaterials. 2008;29(20):2941-2953.

4. Boyer RR, Briggs RD. The use of $\beta$ titanium alloys in the aerospace industry. Journal of Materials Engineering and Performance. 2005;14(6):681-685.

5. Black J. Does corrosion matter? Bone and Joint Journal. 1988;70B(4):517-520.

6. Eisenbarth E, Breme J, Hildebrand H. Einfluss des Vanadiumgehalts von Ti-Al-V-Legierungen. Biomaterialien. 2001;2(4):203-210.

7. Wapner KL. Implications of metallic corrosion in total knee arthroplasty. Clinical Orthopaedics and Related Research. 1991;(271):12-20.

8. Niinomi M, Nakai M, Hieda J. Development of new metallic alloys for biomedical applications. Acta Biomaterialia. 2012;8(11):3888-3903.
9. Valiev RZ, Islamgaliev RK, Alexandrov IV. Bulk nanostructured materials from severe plastic deformation. Progress in Materials Science. 2000;45(2):103-189.

10. Perry MB, Kharoufeh JP, Shekhar S, Cai J, Shankar MR. Statistical characterization of nanostructured materials from severe plastic deformation in machining. IIE Transactions. 2012;44:534-550.

11. Valiev RZ, Alexandrov IV. Nanostructured materials from severe plastic deformation. Nanostructured Materials. 1999;12(14):35-40

12. Zhu YT, Varyukhin V, eds. Nanostructured Materials by HighPressure Severe Plastic Deformation. New York: Springer; 2006.

13. Zhilyaev AP, Nurislamova GV, Kim BK, Baró MD, Szpunar JA, Langdon TG. Experimental parameters influencing grain refinement and microstructural evolution during high-pressure torsion. Acta Materialia. 2003;51(3):753-765.

14. Rauch EF, Portillo J, Nicolopoulos S, Bultreys D, Rouvimov S, Moeck P. Automated nanocrystal orientation and phase mapping in the transmission electron microscope on the basis of precession electron diffraction. Zeitschrift für Kristallographie. 2010;225(2-3):103-109.

15. Dimic I, Cvijovic-Alagic I, Völker B, Hohenwarter A, Pippan $\mathrm{R}$, Veljovic $\mathrm{Ð}$, et al. Microstructure and metallic ion release of pure titanium and Ti-13Nb-13Zr alloy processed by high pressure torsion. Materials \& Design. 2016;91:340-347.

16. Sauvage X, Wilde G, Divinski SV, Horita Z, Valiev RZ. Grain boundaries in ultrafine grained materials processed by severe plastic deformation and related phenomena. Materials Science and Engineering: A. 2012;540:1-12.

17. Edalati K, Matsubara E, Horita Z. Processing Pure Ti by High-Pressure Torsion in Wide Ranges of Pressures and Strain. Metallurgical and Materials Transactions A . 2009;40(9):20792086.

18. Wang YC, Langdon TG. Effect of heat treatment on microstructure and microhardness evolution in a Ti-6Al-4V alloy processed by high-pressure torsion. Journal of Materials Science. 2013;48(13):4646-4652. 